\title{
Tuberculosis Control Concept in Nepal
}

\author{
-DR. JAYA N. GIRI* \\ -DR. D. H. PATTERSON*
}

1. Tuberculosis is not an easy disease to treat in any country. In Nepal, where thc terrain hardly encourages rapid mobility, and the annual expenditure on health per capita is one US dollar, the logistics of providing an effective Tuberculosis Control Programme are difficult but not, fortunately, impossible. The problems are formidable in any field of medicine or surgery, but because TB requires regular tieatment for up to, or beyond, eighteen months, it is, perhaps, a special case.

\section{THE PREVALENCE OF TB}

Not a great deal is known, but some work has been done and is briefly discussed.

(a) House to house surveys have been carried out at the same time as mass BCG vaccination programmes in several districts by TBCP and BNMT. In generaJ, approximately half of the adult population were available for interview, and of these, about $4 \%$ were TB symptomatics, i. e. coughed for more than one month, haemoptysis, chest pain and fever. (Table 1). This gives aprevalence of $0.4-0.5 \%$ for PTB. In one Jilla, Dhankuta, we have broken down the case-finding into ages (Table 2). It can be seen that the number of sputum positives among the $25-40$ year age group is the highest for the number of sputa examined. In our house to house surveys the male population aged 25-40 comprises, howover, the largest age

* MBBS, DTCD (Wales)

FRSH (Eng), FCDP (USA)

Project Leader, T. B. Control Project.

* MBBS, DCH, D. Obsi. R.C.O.G. 
group not available for questioning and therefore for sputum examination. are usually out at work.

(b) Surveys in the Kathmandu valley and in the hills (Dr. Iwamura) showed an infect rate of sputum Pos. TB of 0.82 and 1.78 respoctively (Table 3 and 4).

(c) Dr. Phelps found in Kalimati that of the adult population contacted, $0.75 \%$ sputum positive.

(d) In 1945 Dr. J. Aspin reported that $1 \%$ of Gurkha Recruits had PTB.

(e) Overall prevalence:

Microscopic examination does not quite give $100 \%$ accurate diagnosis of PTB with 3 early morning sputum samples. Often the bacilli count is too low to be delecter without culture. (However, in a clinic, of cases of PTE under therapy, probably figure of $70 \%$ sputum Positive is acceptable.) Below $60 \%$ sputum positive mean that either not enough slides are being examined, or that too many patients being treated on $\mathrm{x}$-lay diagnosis only.

Now, if prevalence surveys show that about $0.5 \%$ of the adult population have sputum positive tuberculosis, the pravalence for all types of the disease, including gland abdominal, and pulmonary sputurn negative may well be $1-2 \%$. (This figure include children.)

\section{THE DIAGNOSIS OF TB}

The pool of infectivity lies in the (usually adult) population who are coughing up the bacilli. Thus, the examination of the sputum of symptomatics is the most important method of sejecting patients for therapy, accuralely. It avoids the two problems that have been encountered in many countries. where TB is common, (i) over-treating and (if under-treating. We, in Dlankuta, have unwittingly been treating two patients who wer sputum negative over the past year with IN.H/TBI. Unfortunately, as time passed it becam clear that the diagnoses were carcinoma of bronchus and Hodgkin's disease respectivej) for neither of these two cases were the TB drugs very helpful. Soinetimes a symptomatio with haemoptysis who is sputum negative has to be troated with anti-iuberculous INH/TB as a trial of therapy. This has to be ascepted as a realistic occustional diagnostic metho in many pats of Nepa! whore $x$-ray farilities ars facking. 
$X-r a y s$ can be usefu! but it is clear that cases of non-TB bronchiectasls, bronchitis etc, $i$ are being treated as TB. As Sir John Crofton showed in the seminar in Kathmandu last February, in a survey among expert radiologists, there was little unanimity on what constituted PTB and a very low correlation of $x$-ray diagnosis with culture results.

GLAND TB.

It often seems easy to diagnose, but it is always well worth examining the scalp and throat, particularly in children witly several weeks history of cnlarged cervical glands, to ensure that the glands are not infected secondarily to the scalp.

\section{TB MENINGITIS.}

This is often difficult to distinguish from aseptic meningitis, or a viral infection The CSF tends to be opalescent, but the important feature is the lower blood sugar level. and AFB may be seen on a sputum Sample as well as in a centrifuged CSF specimen. ABDOMINAL TB.

History, examination of the abdomen and trial of therapy.

\section{THE CONTROL OF TB.}

There are three ways in which TB prevalence may be brought down to an acceptable Jevel in a conmunity:-

(ii) Immunisation.

(b) Case Finding and Treatment.

(c) By improvement in the socio-economic status, (as in Europe in the last century.)

(a) IMMUNISATION (BCG)

Work carried out in the UK on a large scale by MRC has provided data that show that BCG gives Just over $79 \%$ protection against TB. It is not clera in developing countries whether the same figure applies since there are two major differences in the conditions under which the vaccine is given, when such countries are compared with the U. K.:- 
(i) STORAGE OF THE VACCINE AND MAINTENANCE OF THE COLD CHAIN.

1. The life span of $B C G$ freeze dried vaccine is not more than 4 weeks outsi refrigerations.

2. Reconstituted vaccine has a "life" span of only 4 hours in normal field conditions Thus, in Nepal, high temperatures for many months of the ycar may cause an eve nore rapid deterioration in the viability of the vaccine. In addition, lack of skill manpower may mean that refrigeration units are not functioning properil if at all.

(ii) The nutritional status of the children may be too low in an appreciably large section of the population to produce an adequate immune response. Our conces over this has led us to propose a trial of BCG efficacy, to determine whethef the anmual incidence of $T B$ which should fall after a mitss BCG vaccination campaign has the same order of magnitude in the two groups, adequitely nourished and matnouf rished, as it is anticipated it will show before vaccination. In other words, whetheff applying the MRC figures, there is a drop of approximately $80 \%$ in the annuas incidence of TB in both gromps (adequately nourished and mal-nourisheil) under study We anticipate that the study will take about five years for significant data to collected or, perhaps more realistically, for a trend to be demonstrated.

In spite of the problems of storage and refrigeration, it is worth noting that only sample of vaccine, taken from the field, that we have had tested in the U. K., showed a viability count of $50 \%$ more than the minimum required for an eifective vaccine. From 1965-1978, BCG has been carried out by TBCP, BNMT, IHS Missions, FP and $\mathrm{MCH}, \mathrm{EPI}, \mathrm{NTBA}, \mathrm{NCO} / \mathrm{SCF}$ on at total of 3.5 million children.

(b) CASE FINDING AND TREATMENT *

Intensive therapy, particularly applied to the sputum positive members of the commuait provides the quickest methods or reducing the prevalence of all types of $T B$ by reducing the pool of infectivity. The trouble is that a high cure rate has to be attained before th chronic excretors are numerically reduced. (See Table S). It can be scen that unless

* Note: In case finding by micrescony, approximately $40 \%$ of the infective calsts remain wndected unless multiple early morning spurum examples alli examined. 
a cure rate of about $70 \%$ is reached, the chtonic excretor rate of $25 \%$ remains unaltered. And, in the presence of what is termed in the table as "unsatisfactory programme", most of these chronic excretors will be drug resistant also.

The type of therapy is not really relevant as long as it provides a cure rate of about $85-90 \%$, i. e. that of Streptomycin INH/TBI for two months, and INH/TBI only for a further eighteen months. A regime that is $98 \%$ efective is only significantly more helpful when all he TB patients in a community are receiving therapy, and when the defaulting rate is virtually zero. The Table 6 shows the contrast in two hypothetical situations. The first is where there is a high efficacy in the drug regime, but poor compliance on the patients' part, and only a few of the sputum positive patients are under therapy. The second, shows the more marked reduction of TB in the community when there is an effective delivery of TB services, but not so effective or expensive a drug regime.

A further point about therapy is not merely that the patient with bacilli in his sputum is cured as a result of anti-tuberculous drug; but that he becomes culture negative very early on in the treatment. Although bacilli appear in the sputum for up to three months in a patient who is responding to therapy, these bacilli are not infective. After two to fonr weeks' treatment, the microscope may.. demonstrate several bacilli per field, but the culture of the same sputum sample will yield no growth.

With these points in mind, let us have a look at some of Nepal's problems with specific reference to $\mathrm{TB}$, present methods being used to combat the disease, and tentatively suggest further ideas for implementation, discussion, acceptance (or outright rejection.)

(c) SOCJO-ECONOMIC STATUS

The medical profession can only intervene in this particular problem by improvement in the genera' standard of preventive and therapeutic medicine, as well as acting as a pressure group for the political and socio-economic reform where relevant to Nepal's needs.

\section{NEPAL'S PROBLEMS}

(a) The terrain of the country makes communications difficult over the major part. Medical services are difficult to support, and pațients hàve difficulty in reaching curative centres. 
b) There is a doctor/patient ratio of about $1: 37,000$, and of course the ratio is much satisfactory still outside Kathmandu.

(c) Hcalth expenditure is about $12 \mathrm{NCR}$ per annum per capita (as stated earlier) 1.2 liealth budget being spent on TB.

(d) Poor nutrition and perhaps low socio-economic conditions. This has to mean resistance to infection.

(e) Population movements have often meant bringing infection from areas outside (e. g. Assam) into the country.

(f) Availability of drugs in the past and their distribution to treatment centres. Failu request drugs from Kathmandu in time for uninterrupted therapy.

(g) A high defaulting rate, which we will discuss in more detail later.

\section{AVAILABLE FACILITIES}

(a) At present (1978 figures) there are $50 \mathrm{HMG}$ and 15 other hospitals.

(b) 483 health posts, 278 of which have been integrated.

(c) 90 Ayurvedic hospitals and dispensaries.

(d) 40 Centres or Laboratories with a microscope.

(e) $19 \mathrm{x}$-ray units, not all of which are in operation.

(f) Equipment, advice and facilities from WHO, UNICEF, missions and other organisatiof

(g) TBCP set up in 1965 to train, supervise TB drug distribution, advise on conth methods and carry out field work, e. g. BCG, as well as evaluation of progress.

(b) BNMT is responsible (amongst other things) to TBCP for TB control in E. New setting up clinics and laboratories attached to $H M G$ hospitals and BCG vaccination

(i) FP/MCH, NCO/SCF, Integrated Health Services and EPI are involved with BCG.

\section{PROBLEMS WITH MANAGEMENT OF TB}

There is nothing startlingly new in this list; more could probably be added.

First difficulties in the treatment of TB; and then suggested remedies.

(a) Drugs not available in the health posts or hospital.

(b) Inadequate explanation by clinician of the need for long term therapy.

(c) Incorrect managemsat, e. g. changing one drug at a time if resistance is suspected.

(d) Resistance because patient has already been buying tablets from bazar etc. 
for

ndly, problems associated with the management and supervision of patients.

Patients who live more than about three hours away are often either reluetant to

(ii): A distrust of scientific medicine.

(b) Howere to stay, hospitals have no room, and there is no food available. Drugs not Yavailable. If necessary international funds may have to be made available to ensure a regular supply of TB medicines. TB is not the kind of disease that can be treated irregularly because of the danger of resistance. It is not possib'e to stop for a couple of months and ask the patient to return when the drugs are available again. It might cause rejoicing anong the TB bacilli, but not among the patients or medical profession.

b) Inadequate explanation. We, as a profession, are rather apt to thinks that we are slightlysuperior to patients, particularly if we are providing what is described as a free health service. Here as in UK, doctors are liable to behave as if they were the source of the charity. We all make this mistake, and when explaining to a TB patient how essential it is to take regular therapy, it is important to recognise him or her as a fellow hrman being.

c. incorrect management Mistakes are easy to make in TB therapy. A book on TB chemotherapy is being printed in Nepal.

d) Resistance. Over the next year, legislation may be considered neccessary to control the sale of all types of antibiotics without a doctor's prescription. To re-state what was pointed out at the TB seminar last year in Kathmandu, one of our staff visited six pharmacy halls complaining of a cough. When he stated that he had coughed up blood, 
or had the cough for several months, $T B$ medicines were offered on each occasio even rifampicin, two week's course only.

e) Penicillin / Streptomycin. It is possible that Pen/Strep should be recommended unsuitable for use in chest infections in Nepal.

f) Multiple Therapy. We feel that medicines additional to antituberculous therapy a usually confusing. They may have their place when the patient who is anaemic, example, has a course of iron therapy after demonstarble improvement following, sa four weeks' Streptomycin, INH/TB1. Confusion occurs when the patient does a know what medicine has made him better.

g) X-RAYS. Expert radiologists often do not agrce on whether the lesions on an $x$-tayx are due to $\mathrm{TB}$ or, if they are, whether they are active.

ii) THE SUPERVISION OF PATIENTS.

a) Non-compliance; (Table No, 8)

i) Treat the patient as near home as possible, for example, using health posts; This was recommended last year in the TB Seminar, and table number 7 ihus trates our results in Eastern Nepal over the years since we started this.

ii) An adequate supply of TB drugs is essential for continuity of treatment.

iii) Many trials throughout the world have shown conclusively that patient complinnce is proportional to the amount of explanation provided by the clinician in the frst place. We also try to getlonger esiablished patients to talk to the new patients.

iv) Health posts are more likely to support the anti TB programme if givenff encouragement as a result of visits from a Health Inspector and, if he iras time, the doctor.

v) If defaulting still occurs, and however well the clinic is run this is inevitable, IHS has Village Health Workers in Integrated areas, who are taught to traco defaulters. Sometimes initial supervision of VHWs is necessary. Areas that arot not integrated can usually manage by making full use of panchayat authoritit ties or having a defaulier chaser attached to one or even two districts Patio ents who live more than three hours away will use health posts if thesta centres are supplied with medicine and supervision. 
b) A Distrust of seientific medicine. This will: be modified by i) time.

ii) seeing that it really does work.

c) Initial two month therapy. Even when health posts are fully used, there are always a number of patients (usually averaging ten) who need to stay near the hospital for their daily injections. At present, we in BNMT are building some simple hostels in which the patients look after themselves. Since they are sited near the District Hospitals this does he!p to solve the accomodation, if not the food, problems.

We feel that urgent consideration should be paid to this problem particularly in the hilly and mountainous regions, where without some kind of hostel accomodation (not hospital) sputum positive patients cannot receive the initial intensive therapy they need to protect their community as well as to control their own disease.

\section{SUMMARY}

This paper looks at some of the difficulties in TB management. It also attempts to encourage the medical and paramedical professions to regard TB Control as something more than handing a TB suspect a supply of mediciries, rather to regard case finding and case holding as challanges which can be overcome. 


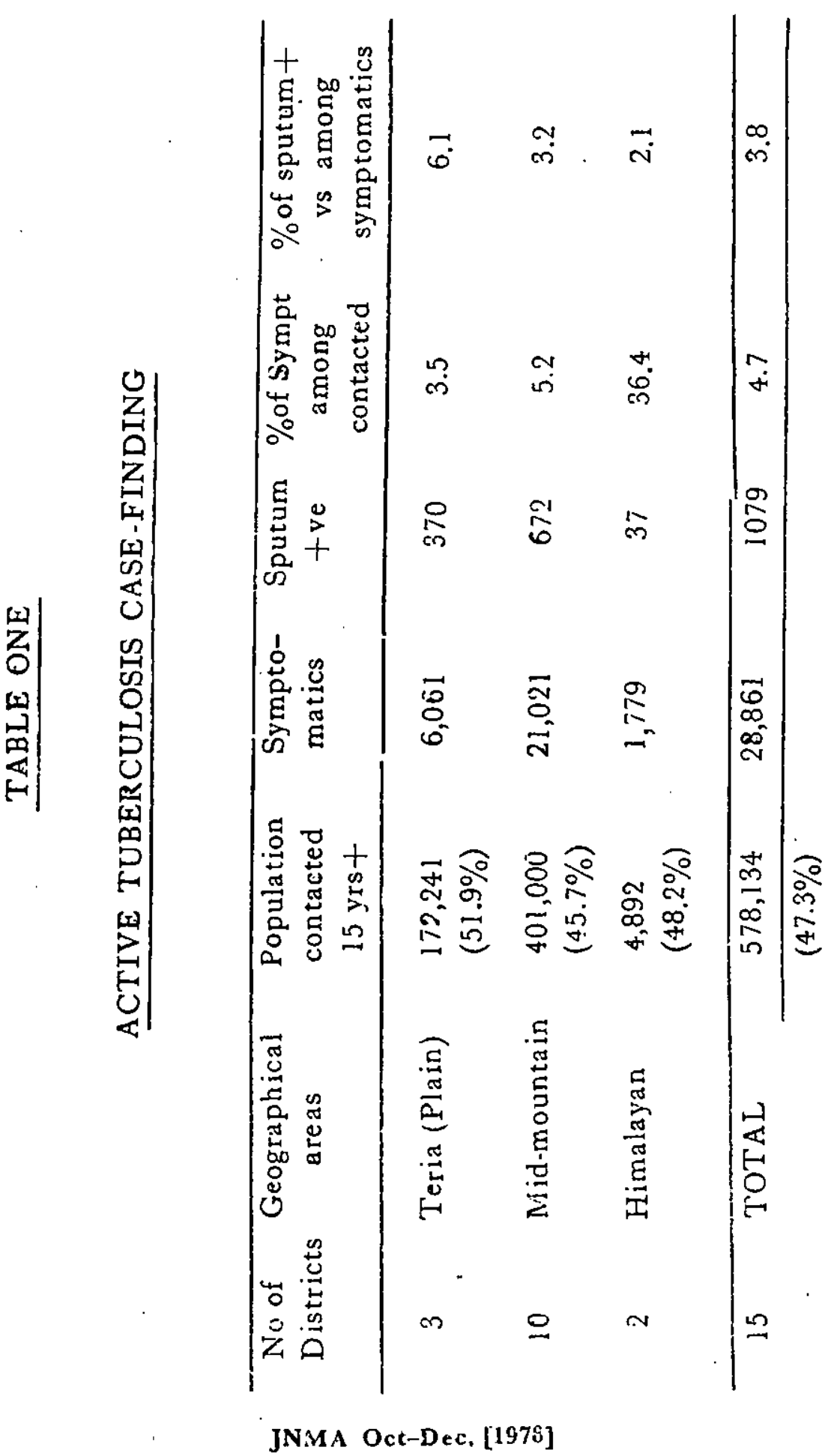




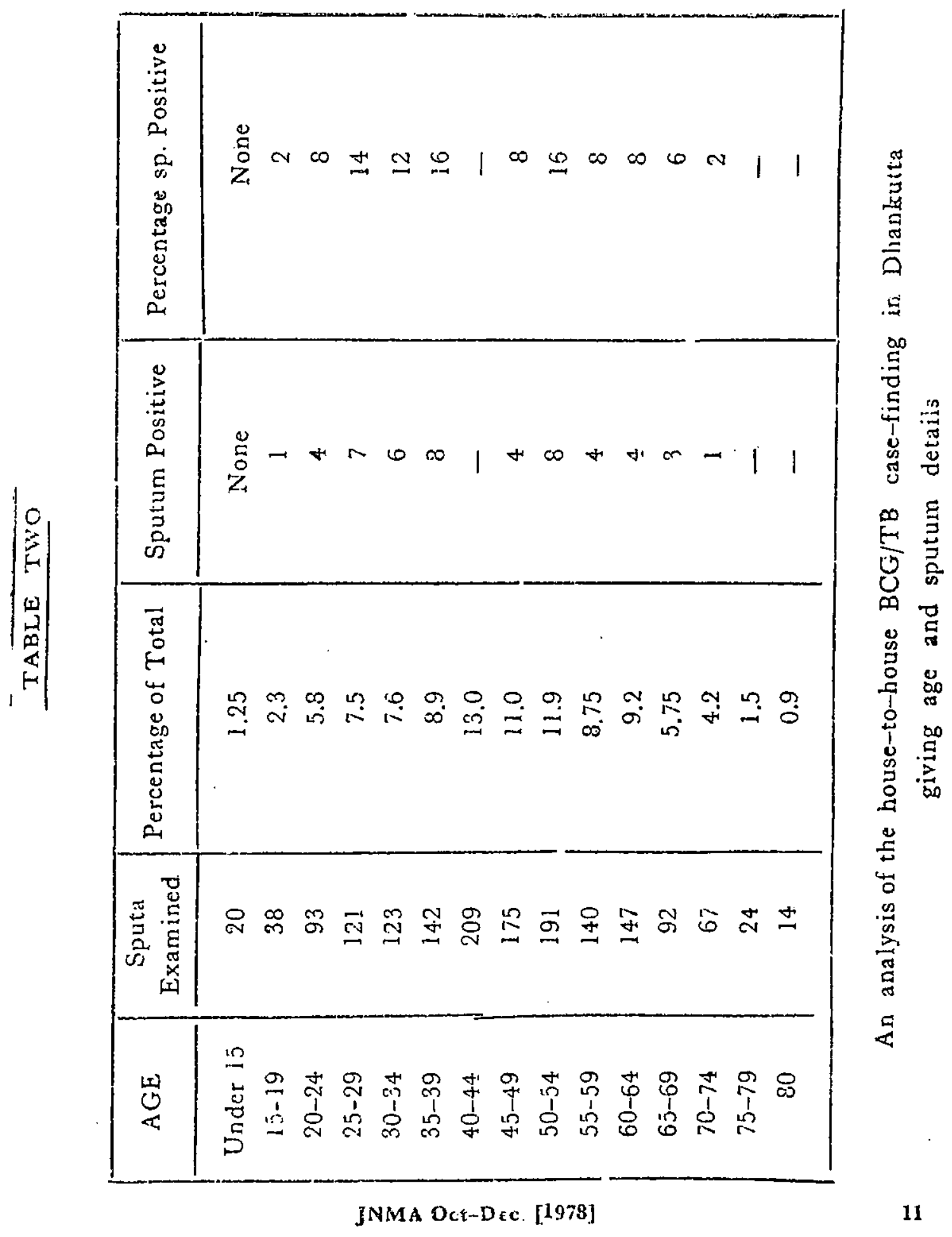




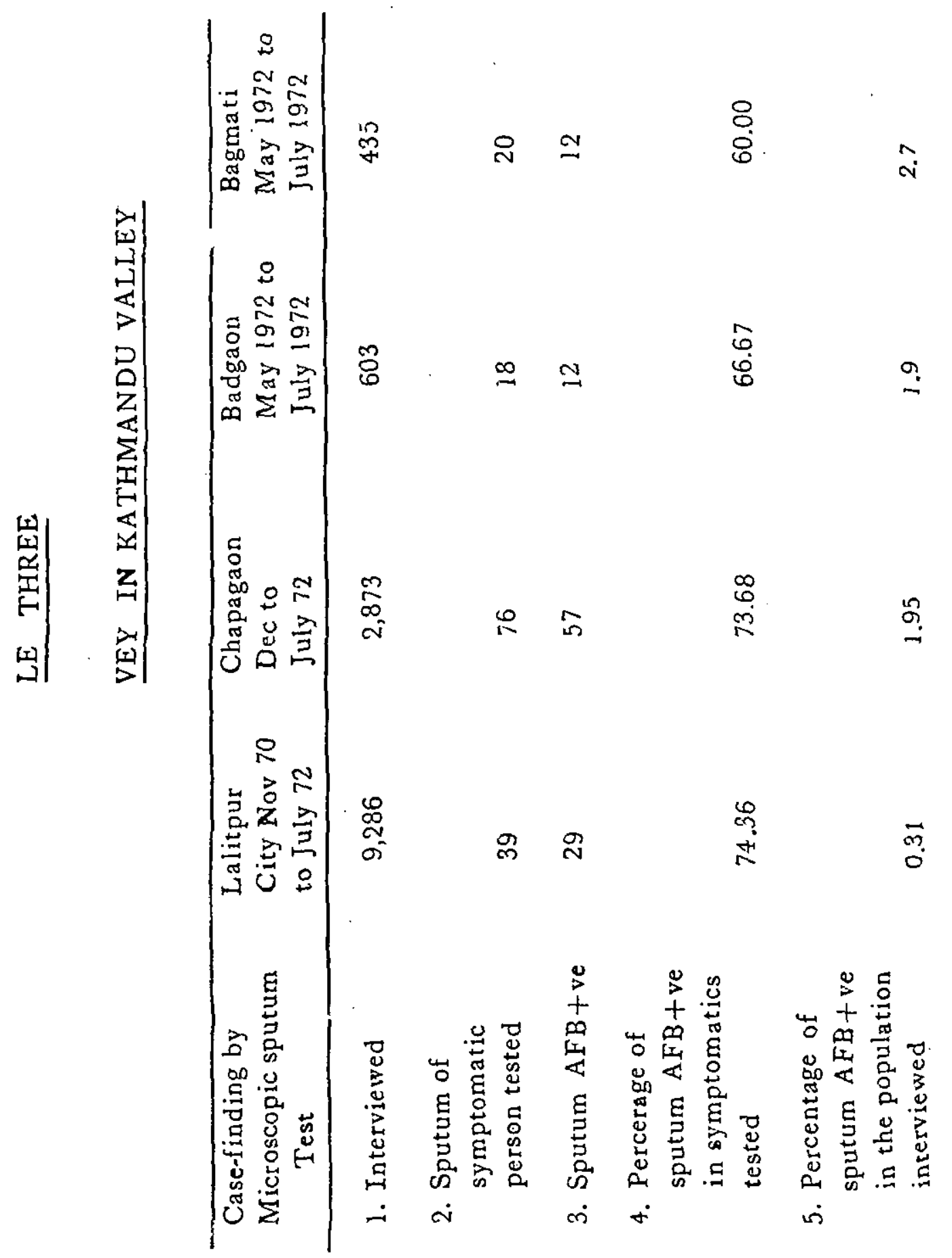

JNMA Oct-Dec. [1978] 


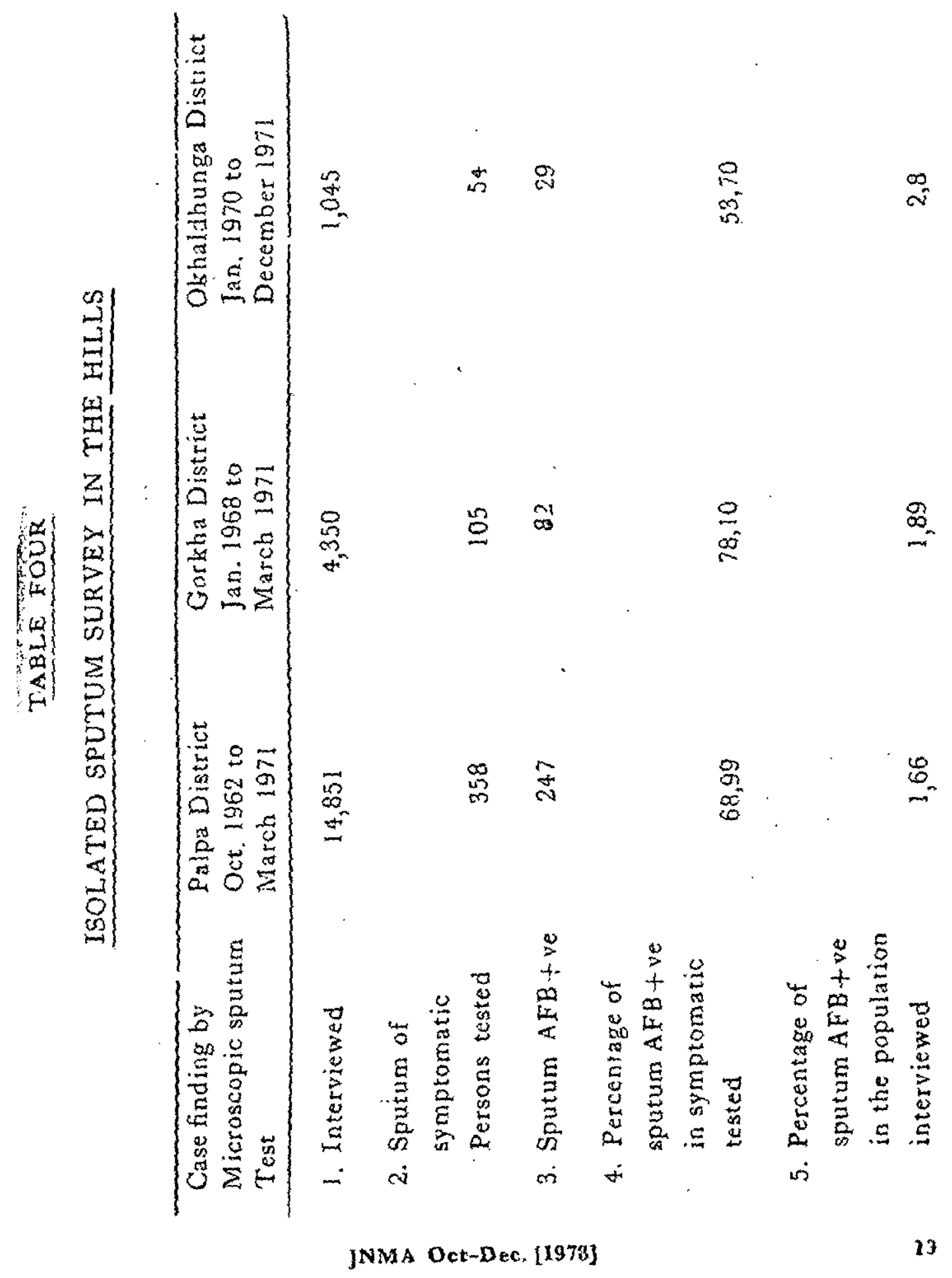




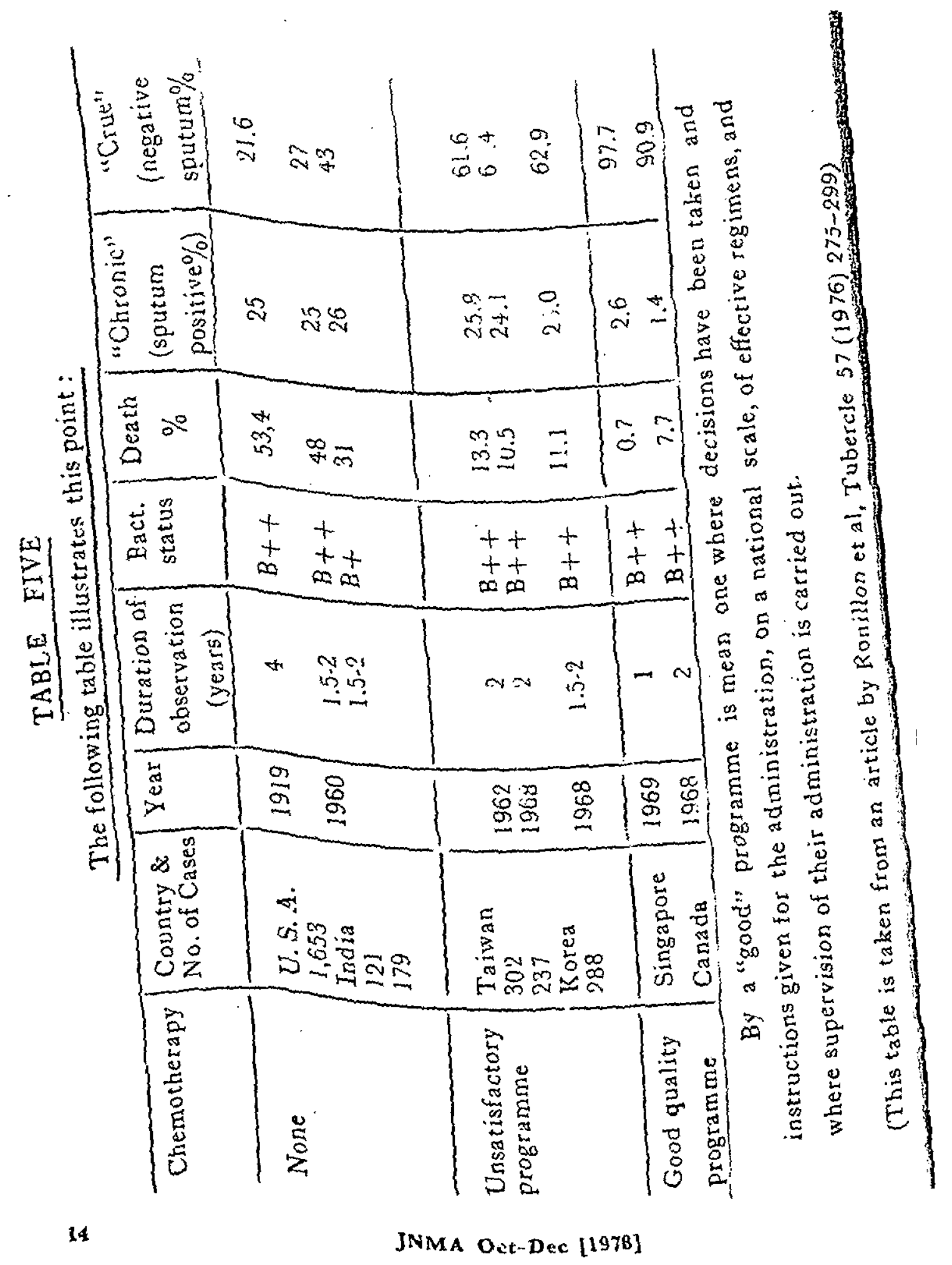




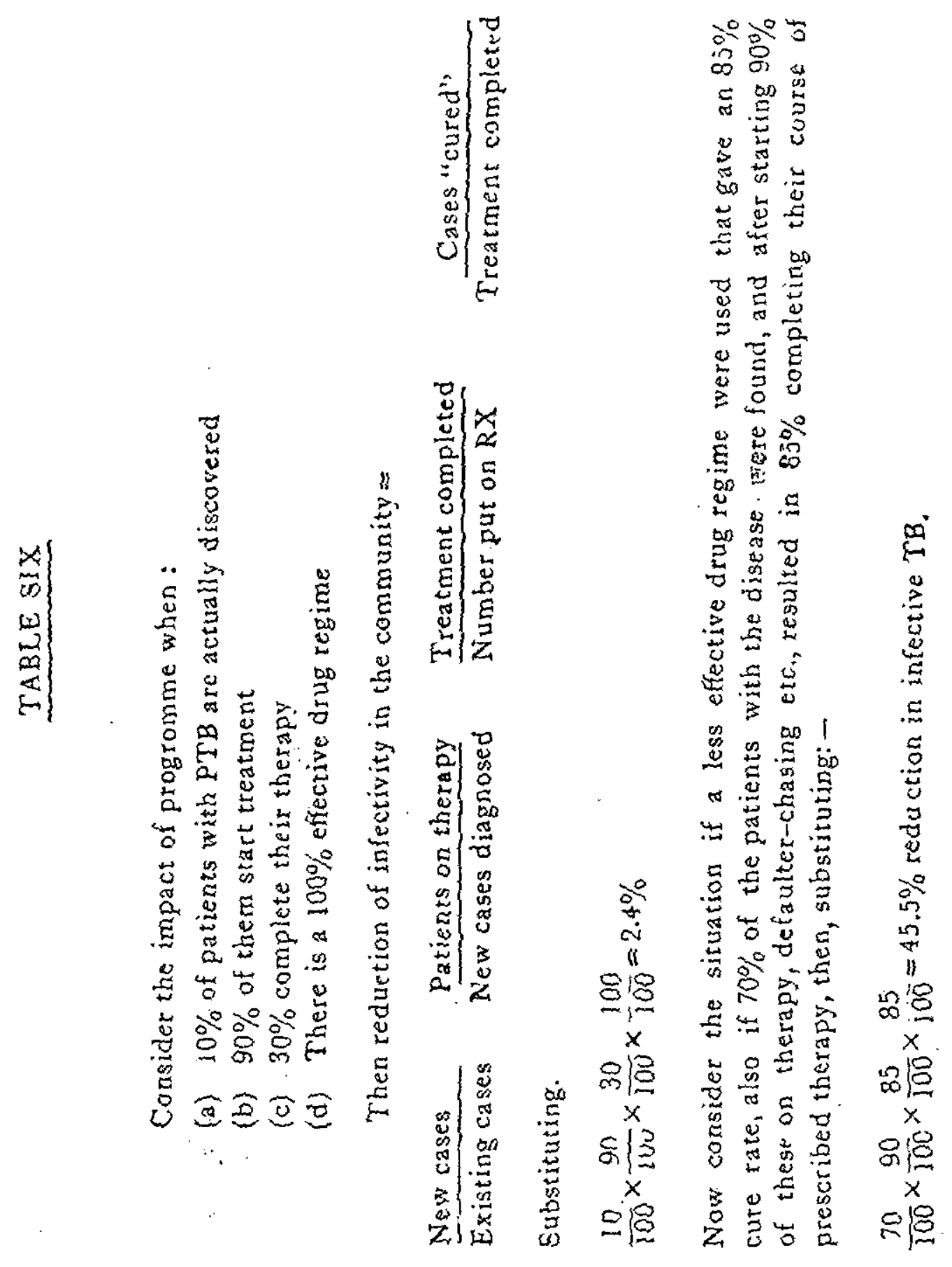

JNMA Oct-Dec. [1978] 


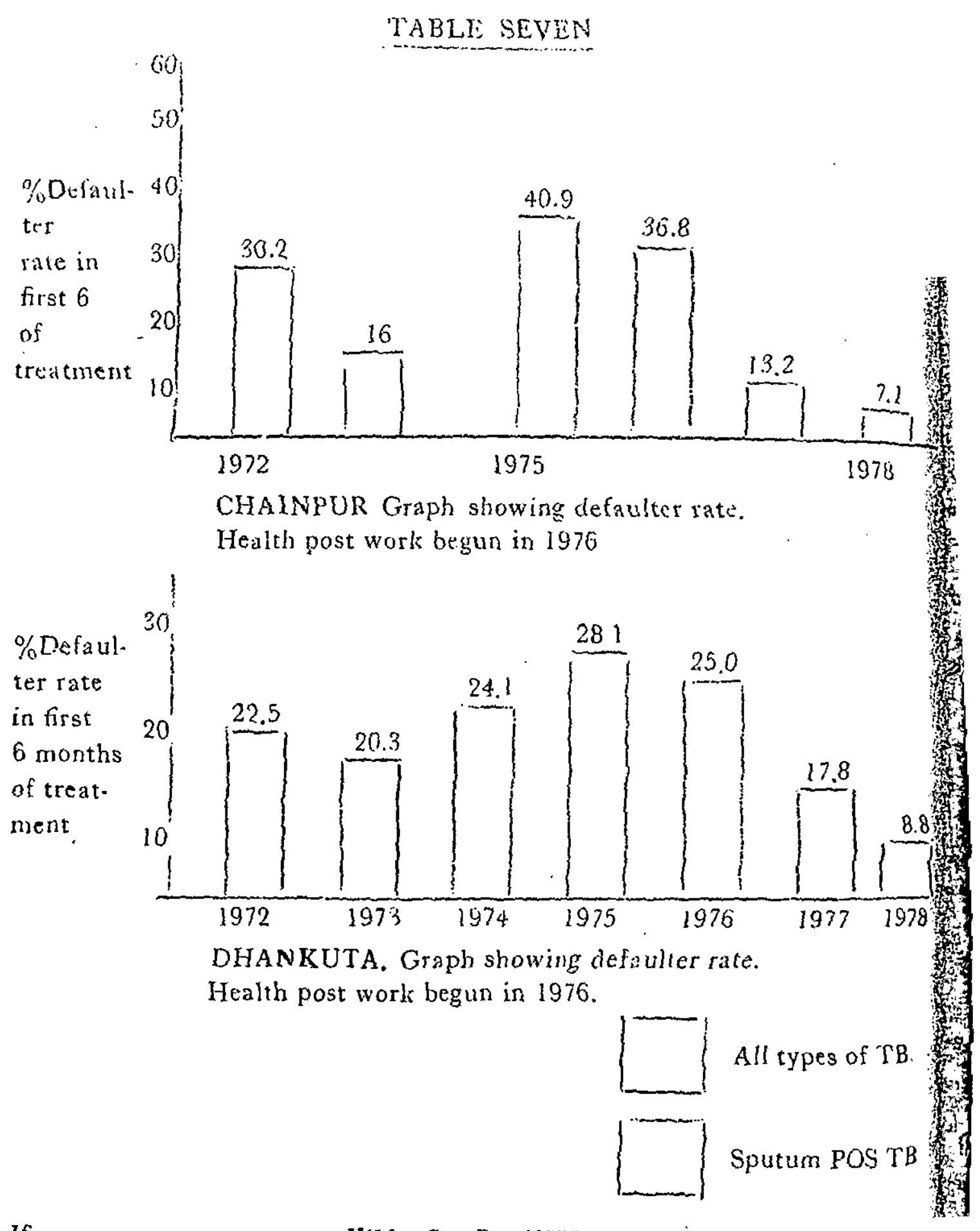

16

JNM. Oct-Dee [1978] 


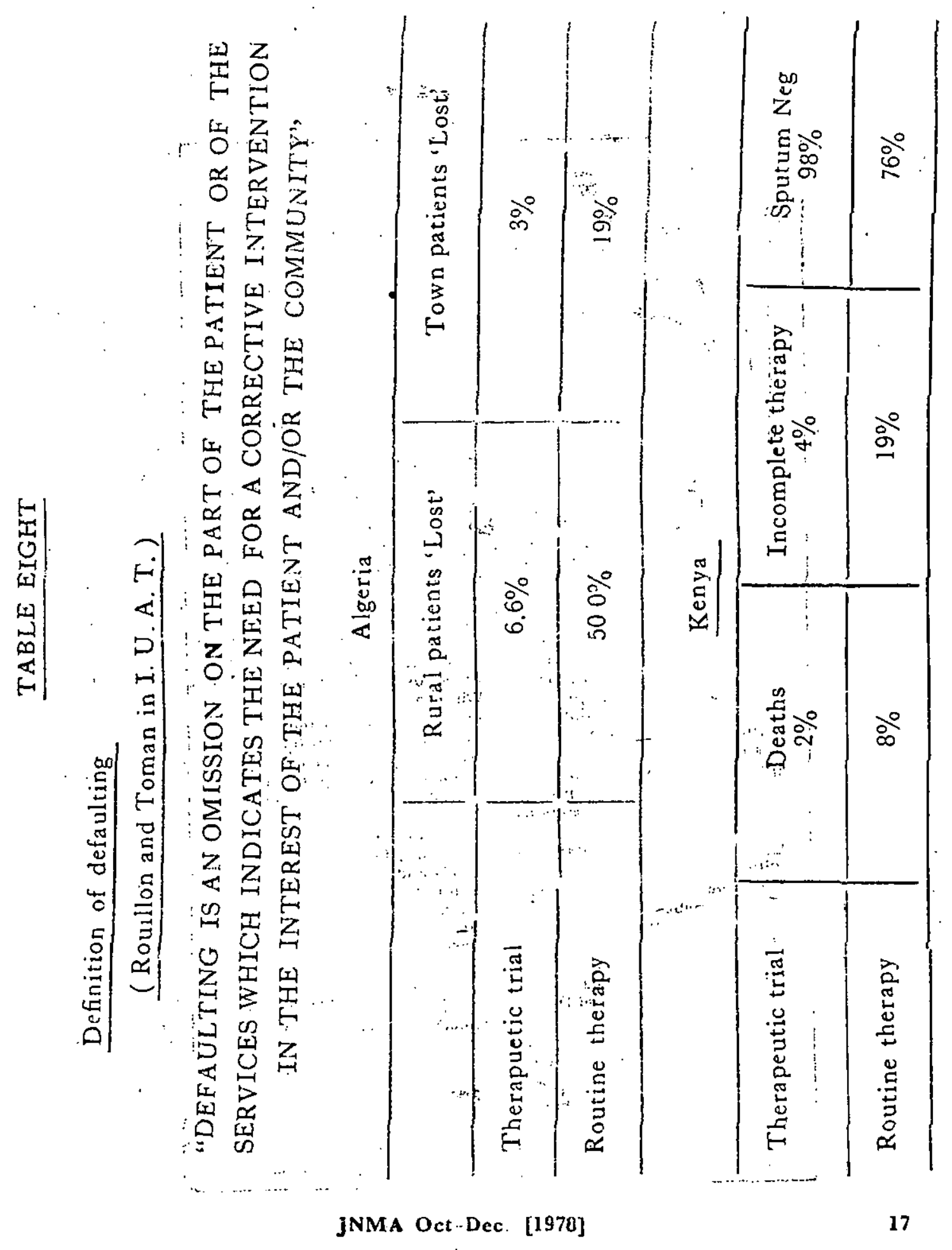




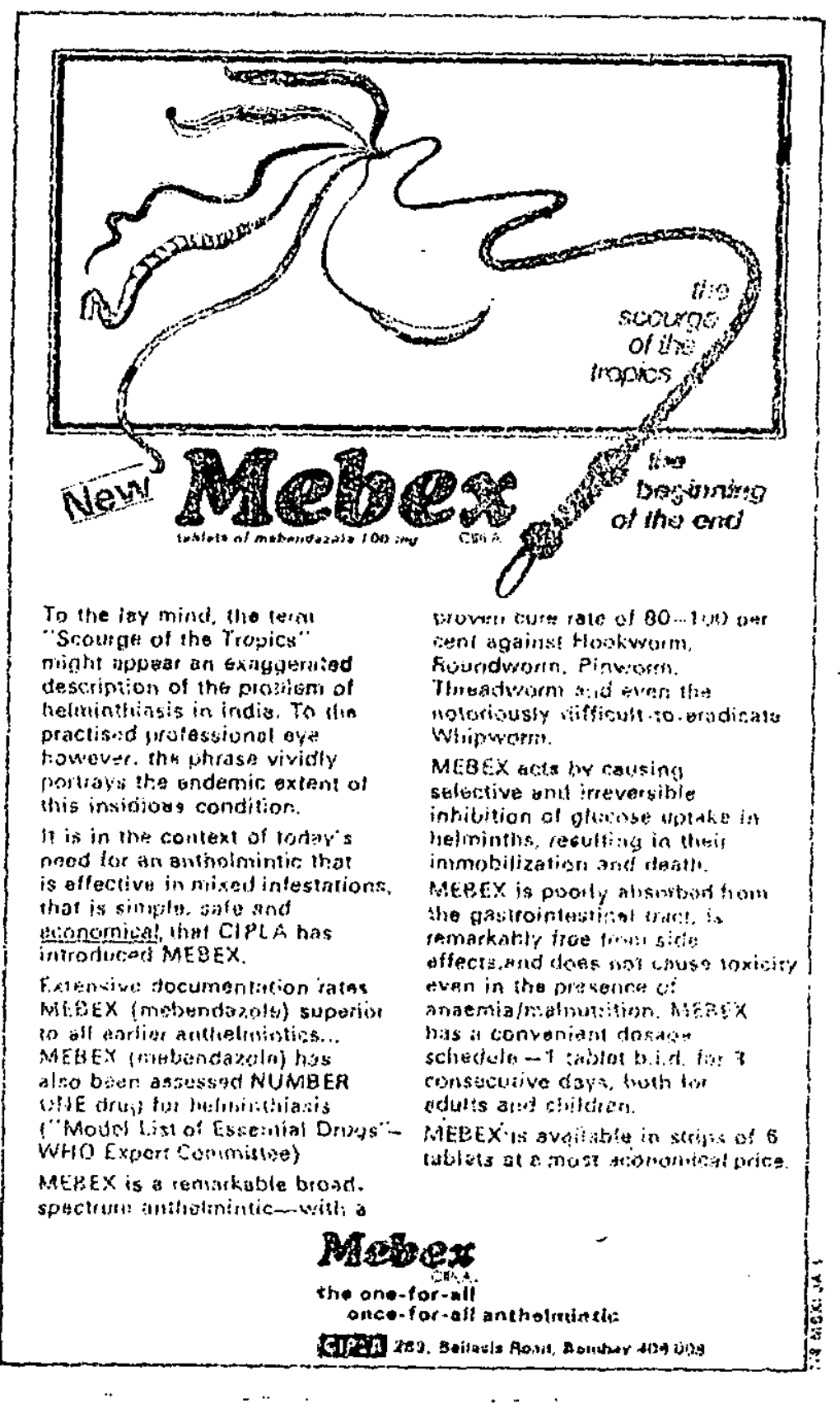

